\title{
Variance components for direct and maternal effects on body weights of Katahdin lambs 1
}

\author{
L. Ngere ${ }^{*}{ }^{2}$ J. M. Burke, $*$ D. R. Notter, $\$$ and J. L. M. Morgan $§$
}

*ARS, USDA, Dale Bumpers Small Farm Research Center, Booneville, AR 72927;

†Oak Ridge Institute for Science and Education, Oak Ridge, TN 37831; †Department of Animal

and Poultry Sciences, Virginia Tech, Blacksburg, 24061; and §Katahdin Hair Sheep Int., Fayetteville, AR, 72702

\begin{abstract}
The aim of this study was to estimate genetic parameters for BW in Katahdin lambs. Six animal models were used to study direct and maternal effects on birth weight (BWT), weaning weight (WWT), and postweaning weight (PWWT) using 41,066 BWT, 33,980 WWT, and 22,793 PWWT records collected over $17 \mathrm{yr}$ in 100 flocks. Models included fixed effects of management group, dam age, type of birth (for BWT) or birth and rearing (for WWT and PWWT), and lamb age at weighing (fitted as a covariate for WWT and PWWT; all $P<$ 0.05). Variance components for random effects were estimated in sequentially more complex models and tested for significance with likelihood-ratio tests. A model that fitted only an additive animal effect overestimated additive variance for all $\mathrm{BW}$, resulting in larger estimates of direct heritability than models that included maternal effects. Maternal effects explained variation $(P<0.05)$ in all BW. Heritability estimates for optimal models were $0.15 \pm 0.01$ for BWT, $0.18 \pm$ 0.02 for WWT, and $0.20 \pm 0.02$ for PWWT. Estimates of maternal heritabilities were 0.14 for BWT, 0.10 for WWT, and 0.06 for PWWT, with SE $=0.01$. Permanent environmental maternal effects explained 4 to $6 \%( \pm 1 \%)$ of total phenotypic variances for these

BW. Litter effects included temporary environmental effects common to littermates and a proportion of the dominance genetic variance and accounted for 16 to $19 \%( \pm 1 \%)$ of phenotypic variance. Correlations between additive direct and maternal genetic effects were -0.14 for BWT, -0.23 for WWT, and -0.04 for PWWT but differed from $0(P<0.05)$ only for WWT. The total heritability predicted the total response in direct and maternal genetic effects from mass selection and was 0.23 for BWT, 0.20 for WWT, and 0.23 for PWWT. Direct and maternal additive, maternal permanent environmental, residual, and phenotypic correlations between BWT and WWT were $0.53 \pm$ $0.05,0.58 \pm 0.06,0.51 \pm 0.06,0.39 \pm 0.01$, and $0.44 \pm$ 0.01 , respectively; those between BWT and PWWT were $0.45 \pm 0.06,0.58 \pm 0.08,0.36 \pm 0.08,0.33 \pm 0.01$, and $0.37 \pm 0.01$ respectively; and those between WWT and PWWT were 0.85, 0.99, 0.92, 0.77, and 0.81, respectively, with $\mathrm{SE} \leq 0.02$. Therefore, both direct and maternal effects had an important impact on BW in Katahdin lambs. Models that included both additive and permanent environmental maternal effects as well as a temporary environmental litter effect should result in more accurate estimates of breeding values and better selection decisions.
\end{abstract}

Key words: body weights, genetic parameters, Katahdin sheep, maternal effects

(C) 2017 American Society of Animal Science. All rights reserved. J. Anim. Sci. 2017.95:3396-3405
doi:10.2527/jas2017.1596

\footnotetext{
${ }^{1}$ Mention of trade names or commercial products in this manuscript is solely for providing specific information and does not imply recommendation or endorsement by the USDA. The USDA prohibits discrimination in all its programs and activities on the basis of race, color, national origin, age, disability, and where applicable, sex, marital status, familial status, parental status, religion, sexual orientation, genetic information, political beliefs, reprisal, or because all or part of an individual's income is derived from any public assistance program. (Not all prohibited bases apply to all programs.) Persons with disabilities who require
}

alternative means for communication of program information (Braille, large print, audiotape, etc.) should contact the USDA's TARGET Center at (202) 720-2600 (voice and TDD). To file a complaint of discrimination, write to USDA, Director, Office of Civil Rights, 1400 Independence Avenue, S.W., Washington, DC 20250-9410 or call (800) 795-3272 (voice) or (202) 720-6382 (TDD). The USDA is an equal opportunity provider and employer.

${ }^{2}$ Corresponding author: lauretta.ngere@gmail.com

Received March 29, 2017.

Accepted May 24, 2017. 


\section{INTRODUCTION}

The potential for growth is of economic importance in sheep breeding, and genetic improvement in growth is normally a major goal (Borg et al., 2007). Production costs are reduced when young lambs rapidly grow, resulting in more profit for the farmer. The influence of the maternal ability of the ewe on lamb growth has been addressed in several studies (Safari et al., 2005; Vanimisetti et al., 2007; Everett-Hincks et al., 2014). The dam contributes to the phenotype of her offspring by providing a sample half of her genes and through genes responsible for expression of maternal traits (Koyuncu and Duru, 2009). In populations with multiple births, it is important to fit the effect of litter, which includes the temporary environmental effects common to litter mates and a proportion of the dominance genetic variance. Ignoring maternal influences leads to upward bias in estimates of $h^{2}$ (Lewis and Beatson, 1999; Koyuncu and Duru, 2009), which could create unrealistic expectations for progress from selection.

The Katahdin is a composite breed of sheep that was developed in the late 1950s in Maine by crossing hair and wool breeds (Wildeus, 1997; http://www.katahdins.org/ [accessed on 3 May 2017]). The Katahdin is a low-maintenance, hardy, and relatively prolific breed that does not require shearing; is comparable to other medium-sized maternal breeds in adult BW and lamb growth; and is relatively resistant to internal parasites (Wildeus, 1997; Vanimisetti et al., 2004). Many studies have estimated variance components for BW in various sheep breeds (Safari et al., 2005). However, studies involving Katahdin hair sheep are limited (Vanimisetti et al., 2007) and have not addressed sources of variation in postweaning weight or considered alternative models for estimation of maternal effects. The objective of this study was, therefore, to estimate genetic parameters for direct and maternal effects influencing birth, weaning, and postweaning BW in Katahdin lambs.

\section{MATERIALS AND METHODS}

\section{Data}

Data for this study were collected between 1998 and 2015 from 100 Katahdin flocks that participated in the U.S. National Sheep Improvement Program (NSIP). Katahdin sheep have been evaluated in the NSIP since 2000, with regular recording of birth, weaning, and postweaning weights (Vanimisetti et al., 2007). The study used data from 41,066 lambs (20,358 males and 20,708 females) sired by 921 rams and born in 23,107 litters from 9,109 dams. Traits investigated were birth weight (BWT; $n=41,066$ ), weaning weight (WWT;
Table 1. Descriptive statistics for BW (kg) and weaning and postweaning ages (d) for Katahdin lambs

\begin{tabular}{lcccrcc}
\hline \hline Measurement & No. & Minimum & Maximum & Mean & SD & CV, \% \\
\hline Birth weight & 41,066 & 2 & 9 & 4.03 & 0.85 & 21 \\
Weaning weight & 33,980 & 7 & 49 & 20.67 & 5.39 & 26 \\
Postweaning weight & 22,793 & 10 & 72 & 31.48 & 8.03 & 26 \\
Weaning age & 33,980 & 42 & 125 & 65.87 & 10.02 & 15 \\
Postweaning age & 22,793 & 91 & 300 & 121.35 & 20.66 & 17 \\
\hline
\end{tabular}

$n=33,980$; recorded at 42 to $125 \mathrm{~d}$ of age), and postweaning weight (PWWT; $n=22,793$; recorded at 91 to $300 \mathrm{~d}$ of age). Data were restricted to single, twin, triplet, and quadruplet lambs $(n=7,807, n=24,186, n=8,445$, and $n=628$, respectively); lambs raised in litters of 1,2 , or 3 ( $n=9,086, n=23,776$, and $n=5,187$, respectively); and dams that were between $10 \mathrm{mo}$ and $10 \mathrm{yr}(126 \mathrm{mo})$ old at lambing. Management of flocks was according to the goals of each farm and was all different.

\section{Statistical Analyses}

Analyses were performed using the ASReml statistical package (Gilmour et al., 2015), presuming convergence when the log likelihood in successive iterations changes less than $0.002 \mathrm{x}$ the current iteration number. All models included the fixed effects of dam age in years (1 to 10) and a management group effect. The BWT model also included an effect of birth type (single, twin, triplet, and quadruplet), and models for WWT and PWWT included a fixed effect of birth-rearing type and a continuous effect of lamb age at weighing. The BWT management group was defined by joint effects of flock, birth year, lamb sex, birth date (using 35-d birth date windows), and an optional BWT management group designation supplied by the flock manager. The WWT management group was derived from the BWT management group by additionally separating castrated and intact males and adding effects of the date of the WWT and an optional WWT management-group designation. The PWWT management group was derived from the WWT management group by adding effects of the date of the PWWT and an optional PWWT management-group designation. Models for all traits included random animal additive genetic effects. Additional random maternal effects were considered by sequentially adding maternal permanent environmental, additive maternal, and maternal temporary environmental (i.e., litter) effects to the base model and by inclusion or exclusion of the covariance between animal and maternal additive genetic effects from models that contained both of these effects.

Six animal models were therefore fitted for each BW:

$$
\mathbf{Y}=\mathbf{X b}+\mathbf{Z}_{\mathbf{a}} \mathbf{a}+\mathbf{e}
$$




$$
\begin{aligned}
& \mathbf{Y}=\mathbf{X b}+\mathbf{Z}_{\mathbf{a}} \mathbf{a}+\mathbf{Z}_{\mathbf{c}} \mathbf{c}+\mathbf{e}, \\
& \mathbf{Y}=\mathbf{X b}+\mathbf{Z}_{\mathbf{a}} \mathbf{a}+\mathbf{Z}_{\mathbf{m}} \mathbf{m}+\mathbf{Z}_{\mathbf{c}} \mathbf{c}+\mathbf{e}, \\
& \mathbf{Y}=\mathbf{X b}+\mathbf{Z}_{\mathbf{a}} \mathbf{a}+\mathbf{Z}_{\mathbf{m}} \mathbf{m}+\mathbf{Z}_{\mathbf{c}} \mathbf{c}+\mathbf{e}(\text { with } \\
& \left.\operatorname{Cov}(\mathbf{a}, \mathbf{m})=\mathbf{A} \sigma_{\mathrm{am}}\right), \\
& \mathbf{Y}=\mathbf{X b}+\mathbf{Z}_{\mathbf{a}} \mathbf{a}+\mathbf{Z}_{\mathbf{m}} \mathbf{m}+\mathbf{Z}_{\mathbf{c}} \mathbf{c}+\mathbf{Z}_{\mathbf{l}} \mathbf{l}+\mathbf{e}, \\
& \text { and } \quad \\
& \mathbf{Y}=\mathbf{X b}+\mathbf{Z}_{\mathbf{a}} \mathbf{a}+\mathbf{Z}_{\mathbf{m}} \mathbf{m}+\mathbf{Z}_{\mathbf{c}} \mathbf{c}+\mathbf{Z}_{\mathbf{l}} \mathbf{l}+\mathbf{e}(\text { with } \\
& \left.\operatorname{Cov}(\mathbf{a}, \mathbf{m})=\mathbf{A} \sigma_{\mathrm{am}}\right),
\end{aligned}
$$

in which $\mathbf{Y}$ is a vector of observation for each trait; $\mathbf{b}$ is a vector of fixed effects; $\mathbf{a}, \mathbf{m}, \mathbf{c}, \mathbf{l}$, and $\mathbf{e}$ are vectors of random additive direct, additive maternal, maternal permanent environmental, litter, and residual effects, respectively; $\mathbf{X}$ is an incidence matrix relating observations to fixed effects; and $\mathbf{Z}_{\mathbf{a}}, \mathbf{Z}_{\mathbf{m}}, \mathbf{Z}_{\mathbf{c}}$, and $\mathbf{Z}_{\mathbf{l}}$ are incidence matrices relating observations to random effects. Additive direct and maternal effects were assumed to be normally distributed with mean of 0 and variances $\mathbf{A} \sigma^{2}{ }_{\mathrm{a}}$ and $\mathbf{A} \sigma^{2}{ }_{m}$, respectively, and for Models [4] and [6], $\operatorname{Cov}(\mathbf{a}, \mathbf{m})$, in which $\mathbf{A}$ is the additive numerator relationship matrix and $\sigma^{2}$ and $\sigma^{2}$ are additive direct genetic variance and additive maternal genetic variance, respectively, and oam is the additive covariance between direct and maternal effects. Maternal permanent environmental, litter, and residual effects were assumed to be normally distributed with means of 0 and variances $\mathbf{I}_{\mathbf{d}} \sigma^{2}$ pe, $\mathbf{I}_{\mathbf{l}} \sigma^{2}$, and $\mathbf{I}_{\mathbf{e}} \sigma^{2}$, respectively, in which $\mathbf{I}_{\mathbf{d}}, \mathbf{I}_{\mathbf{l}}$, and $\mathbf{I}_{\mathbf{e}}$ are identity matrices with dimensions equal to the numbers of dams, litters, and observations, respectively, and $\sigma_{\text {pe }}^{2}$ $\sigma^{2}{ }_{1}$, and $\sigma^{2}{ }_{\mathrm{e}}$ are variances due to maternal permanent environmental, litter, and residual effects, respectively.

The significance of additional random maternal effect in Models [2], [3], and [5] was tested using likelihood-ratio tests to compare the goodness of fit of each of these models with that of the preceding model. A $\chi^{2}$ distribution with $1 \mathrm{df}$ was used to determine significance levels for differences in likelihoods $\left[2\left(\log \mathrm{L}_{1}-\log \mathrm{L}_{0}\right)\right]$, in which $\operatorname{LogL}$ is the logarithm of the likelihood, between sequential models. The significance of the additive direct-maternal additive covariance was determined using likelihood tests with $1 \mathrm{df}$ to compare goodness of fit between Models [3] and [4] and Models [5] and [6].

The total phenotypic variance $\left(\sigma_{p}^{2}\right)$ for each model was calculated as the sum of the variance and covariance components. Direct heritability $\left(h^{2}\right)$ was calculated as $\sigma^{2}{ }_{\mathrm{a}} / \sigma^{2}{ }_{\mathrm{p}}$; maternal heritability $\left(m^{2}\right)$ was calculated as $\sigma^{2}{ }_{\mathrm{m}} /$

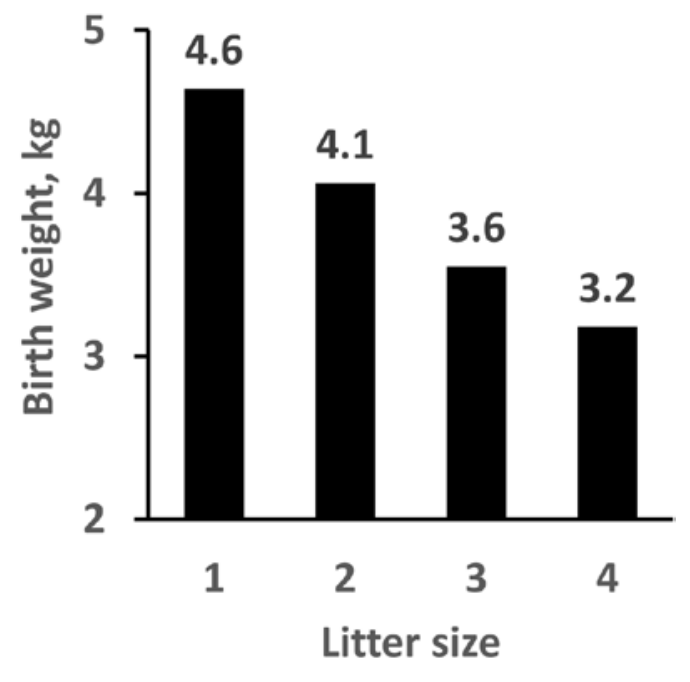

Figure 1. Least squares means for birth weights of Katahdin lambs by litter size. All means differ $(P<0.05)$ and have SE of $\leq 0.03 \mathrm{~kg}$.

$\sigma_{\mathrm{p}}^{2}$; maternal permanent environmental variance as a proportion of $\sigma_{p}^{2}\left(c^{2}\right)$ was calculated as $\sigma^{2}{ }_{c} / \sigma_{p}^{2}$, in which $\sigma^{2}{ }_{c}$ is maternal permanent environmental variance; and litter variance as a proportion of $\sigma_{\mathrm{p}}^{2}\left(l^{2}\right)$ was calculated as $\sigma_{1}^{2} / \sigma_{p}^{2}$. The additive direct-maternal covariance $\left(\sigma_{\mathrm{am}}\right)$ and additive correlation between direct and maternal effect $\left(r_{\mathrm{am}}\right)$ were also estimated. For models that included maternal additive effects, total heritability $\left(h^{2} \mathrm{~T}\right)$ was calculated as $h^{2}{ }_{\mathrm{T}}=\left(\sigma^{2}{ }_{\mathrm{a}}+0.5 \sigma_{\mathrm{m}}^{2}+1.5 \sigma_{\mathrm{am}}\right) / \sigma_{\mathrm{p}}^{2}$ (Willham, 1972). The repeatability of ewe effects across years (assuming different sires in different years) was calculated as $\left(0.25 \sigma^{2}{ }_{\mathrm{a}}+\sigma_{\mathrm{m}}^{2}+\sigma_{\mathrm{c}}^{2}+\sigma_{\mathrm{am}}\right) / \sigma_{\mathrm{p}}^{2}$, and the correlation between full-sib lambs was estimated as $\left(0.5 \sigma^{2}{ }_{\mathrm{a}}+\sigma_{\mathrm{m}}^{2}\right.$ $\left.+\sigma^{2}{ }_{\mathrm{c}}+\sigma^{2}{ }_{1}+\sigma_{\mathrm{am}}\right) / \sigma_{\mathrm{p}}^{2}$. Bivariate analyses were used to estimate additive direct, additive maternal, maternal permanent environmental, residual, and phenotypic covariances and correlations among traits. Bivariate models included the fixed effects used for corresponding univariate analyses and random additive direct, additive maternal, and maternal permanent environmental effects.

\section{RESULTS}

\section{Fixed Effects on $B W$}

Descriptive statistics for BW and ages at the time of recording of WWT and PWWT are shown in Table 1. All fixed effects were significant $(P<0.05)$ for all BW. The BWT decreased $(P<0.01)$ as litter size increased from 1 to 4 (Fig. 1). Means for joint effects of type of birth and rearing (Fig. 2) on WWT and PWWT indicated that lambs born as either singles or twins but raised as singles had greater $(P<0.05)$ WWT and PWWT than those raised as twins. For triplet lambs, WWT and PWWT decreased with increases in the number 

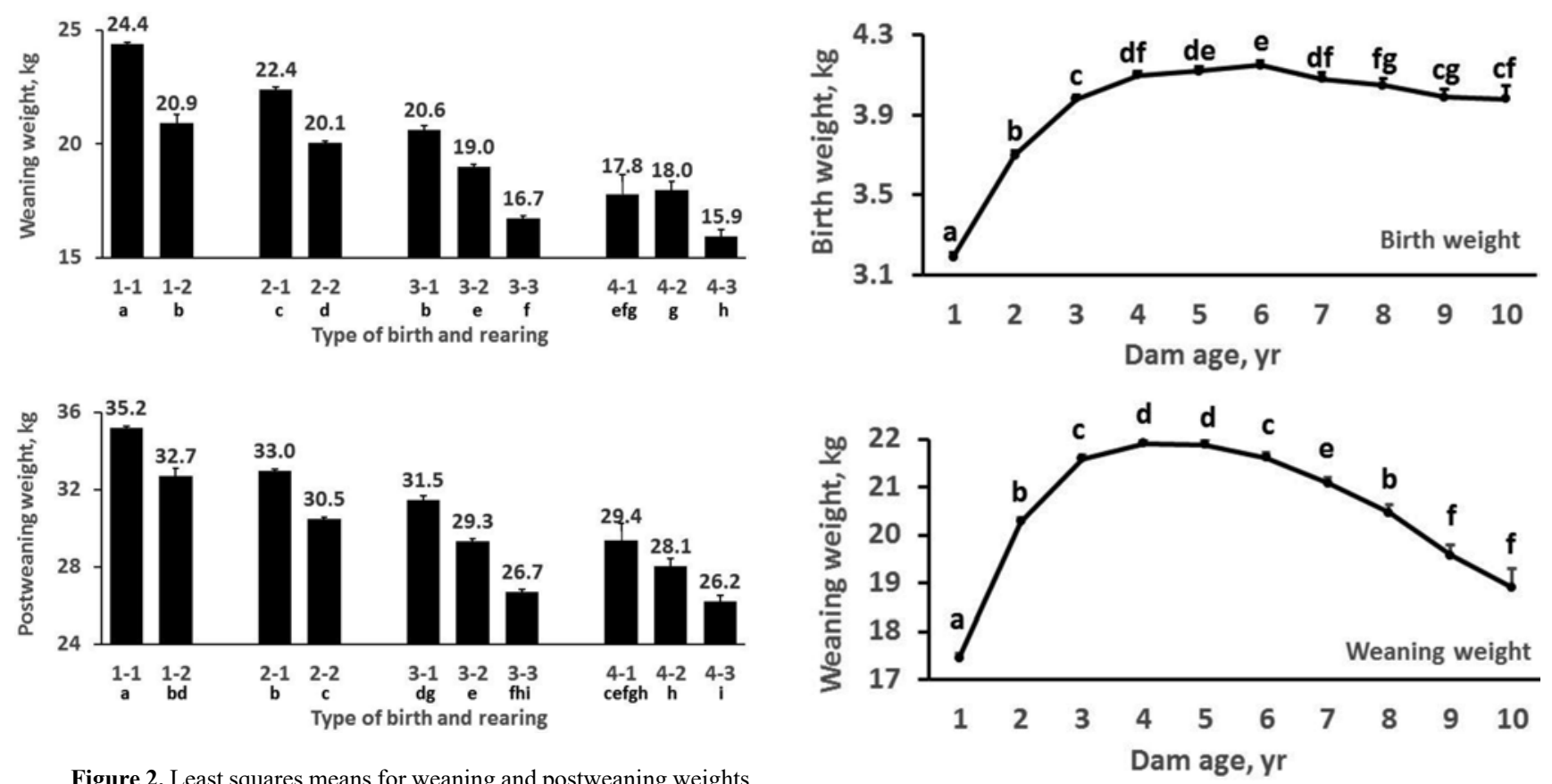

Figure 2. Least squares means for weaning and postweaning weights of Katahdin lambs by type of birth and rearing (e.g., birth-rearing type 2-1 designates a lamb that was born as a twin but reared as a single). ${ }^{\mathrm{a}-\mathrm{i}}$ Means with different letters below the $x$-axis differ $(P<0.05)$.

of lambs raised. No differences in WWT $(P=0.83)$ or PWWT $(P=0.39)$ were detected between lambs born as quadruplets and raised as single or twins, but quadruplet lambs raised as triplets had lower $(P<0.05)$ WWT and PWWT than those raised as singles or twins. Within rearing types, weights consistently decreased $(P<0.05)$ with increases in litter size at birth, although triplet lambs raised as triplets did not differ $(P=0.34)$ in PWWT from quadruplet lambs raised as triplets.

The BWT, WWT, and PWWT all initially increased with increases in dam age (Fig. 3). Maximum BWT were observed at dam ages of 4 to $7 \mathrm{yr}$, but WWT and PWWT began to decline when dam age exceeded $5 \mathrm{yr}$. Regression coefficients describing associations between WWT and PWWT and lamb age were $0.24 \pm 0.003$ and $0.06 \pm 0.003 \mathrm{~kg} / \mathrm{d}$, respectively (both $P<0.001$ ).

\section{Estimates of Genetic Parameters}

Birth Weight. Estimates of variance components for BWT from the 6 models (Table 2) indicated that the additive direct genetic variance was overestimated in Model [1], which did not consider maternal effects. Model [2], which included maternal permanent environmental effects, provided a better fit, explaining $26 \%$ of the total phenotypic variance, and reduced estimates of additive direct variance and direct heritability by about $70 \%$.

Partitioning of the maternal variance into additive maternal and maternal permanent environmental components in Model [3] further improved goodness of fit and indicated that about two-thirds of the maternal

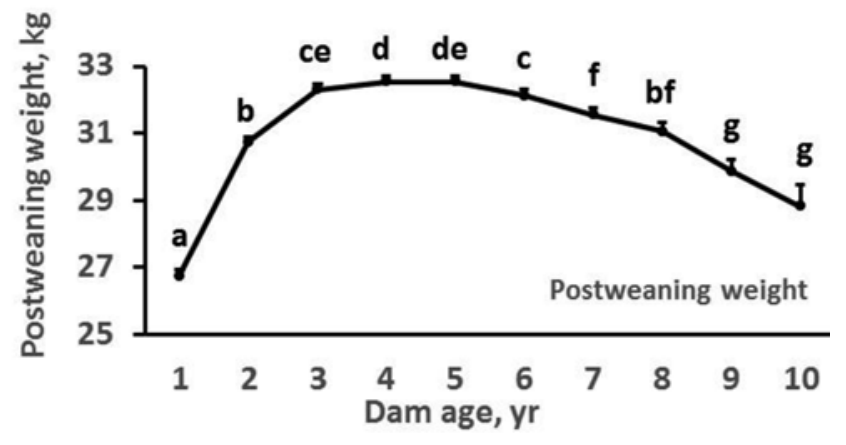

Figure 3. Means for birth, weaning, and postweaning weights of Katahdin lambs by age of dam. ${ }^{\text {a-g }}$ Means with different letters differ $(P<$ 0.05 ). Standard errors for dam age classes of $\leq 6 \mathrm{yr}$ are $\leq 0.02 \mathrm{~kg}$ for birth weight (BWT), $\leq 0.11 \mathrm{~kg}$ for weaning weight (WWT), and $\leq 0.18 \mathrm{~kg}$ for postweaning weight (PWWT).

effect was due to heritable additive maternal differences. Litter effects, in Model [5], were likewise significant $(P<0.05)$ and accounted for $16 \%$ of phenotypic variance. Estimates of direct-maternal additive genetic correlations were low and negative for BWT; inclusion of the direct-maternal additive covariance in Models [4] and [6] did not improve goodness of fit.

Weaning Weight. Maternal effects were clearly important for WWT (Table 3). When maternal effects were ignored (Model [1]), the additive genetic variance for WWT was overestimated by approximately the same proportion as that observed for BWT. Including a permanent environmental effect in Model [2] provided a better fit to the data. Heritability was reduced by $60 \%$ and $c^{2}$ explained $17 \%$ of phenotypic variance.

Model [3], which partitioned maternal effects into additive maternal and maternal permanent environmental components, was significant for WWT. Litter effects (Model [5]) were also significant $(P<$ 
Table 2. Estimates of (co)variance components from different models for birth weight ( $\mathrm{kg}$ ) of Katahdin lambs

\begin{tabular}{|c|c|c|c|c|c|c|}
\hline \multirow[b]{2}{*}{ Item $^{1}$} & \multicolumn{6}{|c|}{ Model } \\
\hline & 1 & 2 & 3 & 4 & 5 & 6 \\
\hline$\overline{\sigma_{a}^{2}}$ & 0.23 & 0.07 & 0.07 & 0.08 & 0.07 & 0.07 \\
\hline$\sigma_{c}^{2}$ & & 0.12 & 0.04 & 0.04 & 0.03 & 0.03 \\
\hline$\sigma_{m}^{2}$ & & & 0.07 & 0.08 & 0.07 & 0.07 \\
\hline$\sigma_{\mathrm{am}}$ & & & & -0.01 & & -0.01 \\
\hline$\sigma_{1}^{2}$ & & & & & 0.07 & 0.07 \\
\hline$\sigma_{\mathrm{e}}^{2}$ & 0.25 & 0.29 & 0.28 & 0.28 & 0.23 & 0.23 \\
\hline$\sigma_{p}^{2}$ & 0.48 & 0.48 & 0.47 & 0.47 & 0.46 & 0.46 \\
\hline$r_{\mathrm{am}}$ & & & & -0.13 & & -0.14 \\
\hline$h_{\mathrm{d}}^{2}(\mathrm{SE})$ & $0.47(0.01)$ & $0.14(0.01)$ & $0.16(0.01)$ & $0.17(0.01)$ & $0.15(0.01)$ & $0.16(0.01)$ \\
\hline$m^{2}(\mathrm{SE})$ & & & $0.15(0.01)$ & $0.17(0.02)$ & $0.14(0.01)$ & $0.15(0.01)$ \\
\hline$c^{2}(\mathrm{SE})$ & & $0.26(0.01)$ & $0.08(0.01)$ & $0.08(0.01)$ & $0.06(0.01)$ & $0.06(0.01)$ \\
\hline$l^{2}(\mathrm{SE})$ & & & & & $0.16(0.01)$ & $0.16(0.01)$ \\
\hline$t_{\mathrm{m}}$ & & 0.29 & 0.28 & 0.28 & 0.26 & 0.23 \\
\hline$t_{\mathrm{fs}}$ & & 0.32 & 0.31 & 0.32 & 0.44 & 0.42 \\
\hline$h_{\mathrm{T}}^{2}$ & & & 0.23 & 0.22 & 0.23 & 0.20 \\
\hline $\log L^{2}$ & $-4,020.34$ & $-3,243.88^{*}$ & $-3,196.54^{*}$ & $-3,194.99$ & $-2,901.68^{*}$ & $-2,900.97$ \\
\hline
\end{tabular}

${ }^{1} \boldsymbol{\sigma}_{\mathrm{a}}^{2}=$ additive direct genetic variance; $\boldsymbol{\sigma}_{\mathrm{c}}{ }_{\mathrm{c}}=$ maternal permanent environmental variance; $\boldsymbol{\sigma}_{\mathrm{m}}^{2}=$ additive maternal genetic variance; $\boldsymbol{\sigma}_{\mathrm{am}}=$ additive covariance between direct and maternal effects; $\boldsymbol{\sigma}_{1}^{2}=$ variance due to litter effects; $\boldsymbol{\sigma}_{\mathrm{e}}^{2}=$ variance due to residual effects; $\boldsymbol{\sigma}_{\mathrm{p}}^{2}=$ phenotypic variance; ram $=$ additive correlation between direct and maternal effect; $h_{\mathrm{d}}{ }_{\mathrm{d}}=$ direct heritability; $m^{2}=$ maternal heritability; $c 2=$ maternal permanent environmental variance as a proportion of $\boldsymbol{\sigma}_{\mathrm{p}}^{2} ; l^{2}=$ litter variance as a proportion of $\boldsymbol{\sigma}_{\mathrm{p}}^{2} ; t_{\mathrm{m}}=$ across-year repeatability of ewe effects $\left[\left(0.25 \boldsymbol{\sigma}^{2}{ }_{\mathrm{a}}+\boldsymbol{\sigma}_{\mathrm{m}}^{2}+\boldsymbol{\sigma}_{\mathrm{c}}^{2}+\boldsymbol{\sigma}_{\mathrm{am}}\right) / \boldsymbol{\sigma}_{\mathrm{p}}^{2}\right]$; $t_{\mathrm{fs}}=$ full-sib correlation $\left[\left(0.5 \boldsymbol{\sigma}_{\mathrm{a}}^{2}+\boldsymbol{\sigma}_{\mathrm{m}}^{2}+\boldsymbol{\sigma}_{\mathrm{c}}^{2}+\boldsymbol{\sigma}_{1}{ }_{1}+\boldsymbol{\sigma}_{\mathrm{am}}\right) / \boldsymbol{\sigma}_{\mathrm{p}}^{2}\right] ; h_{\mathrm{T}}^{2}=$ total heritability $\left[\left(\boldsymbol{\sigma}_{\mathrm{a}}^{2}+0.5 \boldsymbol{\sigma}_{\mathrm{m}}^{2}+1.5 \boldsymbol{\sigma}_{\mathrm{am}}\right) / \boldsymbol{\sigma}_{\mathrm{p}}^{2}\right]$; LogL= logarithm of the likelihood.

${ }^{2}$ Significance levels of alternative models were determined by comparing sequential changes in LogL for Models [1], [2], [3], and [5] and by comparing Models [3] and [4] and Models [5] and [6] to test effects of $\sigma_{\mathrm{am}}$.

$* P<0.05$.

0.05) for WWT and accounted for a somewhat larger proportion of phenotypic variance for WWT compared with BWT. Estimates of the additive direct-maternal covariance from Models [4] and [6] were negative and significant and yielded moderate, negative estimates of additive direct-maternal correlation. Negative estimates of $\sigma_{\mathrm{am}}$ were also associated with small increases in estimates of direct and maternal heritabilities but slightly lower total heritabilities. Model [6] was, therefore, the most appropriate model for WWT. The estimate of maternal heritability from this model was about $56 \%$ of that for direct heritability. Estimates of total heritability, repeatability of ewe performance, and full-sib correlation were modest and relatively consistent across models.

Postweaning Weight. Maternal effects were also significant for PWWT (Table 4). When maternal effects were ignored (Model [1]), the additive variance was overestimated by about the same proportion observed for BWT and WWT. In Model [2], heritability was reduced by $60 \%$ compared with Model [1] and permanent environmental effects accounted for $15 \%$ of the phenotypic variance. Model [3] indicated that additive maternal and maternal permanent environmental variances accounted for approximately equal proportions of phenotypic variance in PWWT. However, Model [5] yielded a relatively large and significant estimate of litter effects and resulted in a 50\% reduction in $c^{2}$ relative to Model [3]. Estimates of the covariance between ad- ditive direct and maternal effect in Models [4] and [6] were negative but small and not significant. Model [5] was, therefore, the most appropriate model for PWWT.

\section{Correlation Estimates}

Inclusion of litter effects in bivariate models resulted in convergence errors that prevented estimation of covariances between litter effects for different BW. Litter effects were therefore excluded from all bivariate models. Additive direct, additive maternal, maternal permanent environmental, residual, and phenotypic correlations between BWT, WWT, and PWWT (Table 5) were all positive and significant. Phenotypic correlations were lower than additive genetic correlations, and additive maternal correlations were greater than correlations between maternal permanent environmental effects. Birth weight had larger correlations with WWT than with PWWT. The largest correlations were between WWT and PWWT. The maternal genetic correlation between BWT and PWWT was moderate and the same as that between BWT and WWT, whereas the genetic and phenotypic correlations between BWT and PWWT were slightly lower than those between BWT and WWT. Permanent environmental correlations were similar to additive maternal correlation for adjacent weights but lower between BWT and PWWT. 
Table 3. Estimates of (co)variance components from different models for weaning weights (kg) of Katahdin lambs

\begin{tabular}{|c|c|c|c|c|c|c|}
\hline \multirow[b]{2}{*}{ Item $^{1}$} & \multicolumn{6}{|c|}{ Model } \\
\hline & 1 & 2 & 3 & 4 & 5 & 6 \\
\hline$\overline{\sigma_{a}^{2}}$ & 4.99 & 1.97 & 2.02 & 2.32 & 1.79 & 2.07 \\
\hline$\sigma_{c}^{2}$ & & 1.97 & 0.86 & 0.90 & 0.45 & 0.49 \\
\hline$\sigma_{\mathrm{m}}^{2}$ & & & 0.99 & 1.20 & 0.91 & 1.10 \\
\hline$\sigma_{\mathrm{am}}$ & & & & -0.39 & & -0.35 \\
\hline$\sigma_{1}^{2}$ & & & & & 2.18 & 2.18 \\
\hline$\sigma^{2}$ & 6.95 & 7.72 & 7.58 & 7.42 & 6.07 & 5.93 \\
\hline$\sigma_{p}^{2}$ & 11.94 & 11.67 & 11.44 & 11.44 & 11.40 & 11.40 \\
\hline$r_{\mathrm{am}}$ & & & & -0.23 & & -0.23 \\
\hline$h^{2}{ }_{\mathrm{d}}(\mathrm{SE})$ & $0.42(0.01)$ & $0.17(0.02)$ & $0.18(0.02)$ & $0.20(0.02)$ & $0.16(0.02)$ & $0.18(0.02)$ \\
\hline$m^{2}(\mathrm{SE})$ & & & $0.09(0.01)$ & $0.10(0.01)$ & $0.08(0.01)$ & $0.10(0.01)$ \\
\hline$c^{2}(\mathrm{SE})$ & & $0.17(0.01)$ & $0.08(0.01)$ & $0.08(0.01)$ & $0.04(0.01)$ & $0.04(0.01)$ \\
\hline$l^{2}(\mathrm{SE})$ & & & & & $0.19(0.01)$ & $0.19(0.01)$ \\
\hline$t_{\mathrm{m}}$ & & 0.21 & 0.21 & 0.20 & 0.16 & 0.15 \\
\hline$t_{\mathrm{fs}}$ & & 0.25 & 0.25 & 0.25 & 0.39 & 0.39 \\
\hline$h^{2}{ }_{\mathrm{T}}$ & & & 0.22 & 0.20 & 0.20 & 0.18 \\
\hline $\log L^{2}$ & $-5,194.31$ & $-4,869.43^{*}$ & $-4,835.73^{*}$ & $-4,832.23 *$ & $-4,575.12 *$ & $-4,572.09^{*}$ \\
\hline
\end{tabular}

${ }^{1} \boldsymbol{\sigma}_{\mathrm{a}}^{2}=$ additive direct genetic variance; $\boldsymbol{\sigma}_{\mathrm{c}}^{2}=$ maternal permanent environmental variance; $\boldsymbol{\sigma}_{\mathrm{m}}^{2}=$ additive maternal genetic variance; $\boldsymbol{\sigma}_{\mathrm{am}}=$ additive covariance between direct and maternal effects; $\boldsymbol{\sigma}_{1}{ }_{1}=$ variance due to litter effects; $\boldsymbol{\sigma}_{\mathrm{e}}^{2}=$ variance due to residual effects; $\boldsymbol{\sigma}_{\mathrm{p}}^{2}=$ phenotypic variance; ram $=$ additive correlation between direct and maternal effect; $h_{\mathrm{d}}{ }_{\mathrm{d}}=$ direct heritability; $\mathrm{m}^{2}=$ maternal heritability; $c^{2}=$ maternal permanent environmental variance as a proportion of $\boldsymbol{\sigma}_{\mathrm{p}}^{2} ; l^{2}=$ litter variance as a proportion of $\boldsymbol{\sigma}_{\mathrm{p}}^{2} ; t_{\mathrm{m}}=$ across-year repeatability of ewe effects $\left[\left(0.25 \boldsymbol{\sigma}^{2}{ }_{\mathrm{a}}+\boldsymbol{\sigma}_{\mathrm{m}}^{2}+\boldsymbol{\sigma}_{\mathrm{c}}^{2}+\boldsymbol{\sigma}_{\mathrm{am}}\right) / \boldsymbol{\sigma}_{\mathrm{p}}^{2}\right]$;

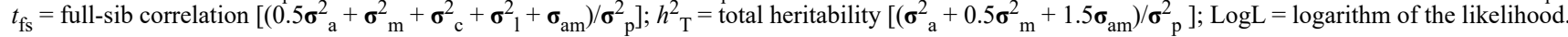

${ }^{2}$ Significance levels of alternative models were determined by comparing sequential changes in LogL for Models [1], [2], [3], and [5] and by comparing Models [3] and [4] and Models [5] and [6] to test effects of $\boldsymbol{\sigma}_{\mathrm{am}}$.

$* P<0.05$.

\section{DISCUSSION}

The Katahdin breed is a relatively new breed in the United States (Wildeus, 1997), was developed from crosses between temperate wool and tropical Caribbean hair breeds, and is one of the most active breeds in the NSIP. Variation among sheep breeds in typical levels of management and feeding, production environments, and genetic potentials for growth indicate a need to derive breed-specific estimates of adjustment factors and genetic parameters to allow optimal selection decisions. Estimation of genetic parameters for the Katahdin breed is also desirable because of the crossbreed origin and diverse founder breeds represented in the Katahdin.

As expected, BWT of Katahdin lambs declined as the litter size increased. Twin lambs were most numerous in these data, and BWT of twin lambs were $11 \%$ lighter than those of single lambs and 14 and $28 \%$ heavier than those of triplet and quadruplet lambs, respectively. The $11 \%$ difference in BWT between single and twin lambs was similar to that observed in NSIP Polypay lambs by Notter et al. (2005), but average BWT for triplet and quadruplet Polypay lambs were 18 and 34\% less, respectively, than those of twin lambs. Notter and Brown (2015) reported that BWT of twin Suffolk lambs born in NSIP flocks averaged $18 \%$ less than those of single lambs and
$18 \%$ more than those of triplet lambs. Variation in BWT across litter size classes was therefore less for Katahdin lambs than for Suffolk and Polypay lambs. Birth weights of Katahdin lambs were heaviest for 4- through 7-yr-old ewes and declined relatively rapidly in younger ewes but much more slowly in older ewes. A similar pattern was reported for Polypay lambs (Notter et al., 2005). Progeny of yearling Katahdin ewes had BWT that were 22\% less than BWT of progeny of 4- through 7-yr-old ewes whereas BWT for progeny of Polypay yearling ewes were $25 \%$ less than BWT of progeny of 4- through 7-yr-old ewes (Notter et al., 2005). However, Notter and Brown (2015) reported that BWT for single and twin lambs by yearling Suffolk ewes were only $19 \%$ less than those of progeny of 3- through 6-yr-old ewes.

Effects of type of birth and rearing on WWT of Katahdin lambs were similar to those observed for other NSIP breeds (Bradford, 2003) and were, in most cases, intermediate to those observed for generally more extensively managed Targhee lambs and generally more intensively managed Suffolk and Polypay lambs. Changes in WWT associated with differences in dam age were broadly similar to those observed in Polypay lambs (Notter et al., 2005). However, Katahdin lambs from yearling ewes had WWT that were $20 \%$ less than those of 3- through 6-yr-old ewes whereas Polypay (Notter et al., 2005) and Suffolk (Notter and Brown, 
Table 4. Estimates of (co)variance components from different models for postweaning weight (kg) of Katahdin lambs

\begin{tabular}{|c|c|c|c|c|c|c|}
\hline \multirow[b]{2}{*}{ Item $^{1}$} & \multicolumn{6}{|c|}{ Model } \\
\hline & 1 & 2 & 3 & 4 & 5 & 6 \\
\hline$\overline{\sigma_{a}^{2}}$ & 10.01 & 4.56 & 4.71 & 4.86 & 4.33 & 4.42 \\
\hline$\sigma_{c}^{2}$ & & 3.41 & 1.78 & 1.80 & 0.94 & 0.95 \\
\hline$\sigma_{m}^{2}$ & & & 1.43 & 1.52 & 1.34 & 1.39 \\
\hline$\sigma_{\mathrm{am}}$ & & & & -0.18 & & -0.10 \\
\hline$\sigma_{1}^{2}$ & & & & & 3.92 & 3.92 \\
\hline$\sigma_{\mathrm{e}}^{2}$ & 13.12 & 14.56 & 14.23 & 14.16 & 11.59 & 11.55 \\
\hline$\sigma_{p}^{2}$ & 23.13 & 22.56 & 22.16 & 22.16 & 22.13 & 22.13 \\
\hline$r_{\mathrm{am}}$ & & & & -0.06 & & -0.04 \\
\hline$h^{2}{ }_{\mathrm{d}}(\mathrm{SE})$ & $0.43(0.02)$ & $0.20(0.02)$ & $0.21(0.02)$ & $0.22(0.03)$ & $0.20(0.02)$ & $0.20(0.02)$ \\
\hline$m^{2}(\mathrm{SE})$ & & & $0.06(0.01)$ & $0.07(0.01)$ & $0.06(0.01)$ & $0.06(0.01)$ \\
\hline$c^{2}(\mathrm{SE})$ & & $0.15(0.01)$ & $0.08(0.01)$ & $0.08(0.01)$ & $0.04(0.01)$ & $0.04(0.01)$ \\
\hline$l^{2}(\mathrm{SE})$ & & & & & $0.18(0.01)$ & $0.18(0.01)$ \\
\hline$t_{\mathrm{m}}$ & & 0.20 & 0.20 & 0.20 & 0.15 & 0.15 \\
\hline$t_{\mathrm{fs}}$ & & 0.25 & 0.20 & 0.35 & 0.38 & 0.38 \\
\hline$h^{2}$ & & & 0.25 & 0.24 & 0.23 & 0.22 \\
\hline $\log L^{2}$ & $-2,986.26$ & $-2,857.59^{*}$ & $-2,831.69 *$ & $-2,831.57$ & $-2,696.70^{*}$ & $-2,696.66$ \\
\hline
\end{tabular}

${ }^{1} \boldsymbol{\sigma}_{\mathrm{a}}^{2}=$ additive direct genetic variance; $\boldsymbol{\sigma}_{\mathrm{c}}{ }_{\mathrm{c}}=$ maternal permanent environmental variance; $\boldsymbol{\sigma}_{\mathrm{m}}^{2}=$ additive maternal genetic variance; $\boldsymbol{\sigma}_{\mathrm{am}}=$ additive covariance between direct and maternal effects; $\boldsymbol{\sigma}_{1}^{2}=$ variance due to litter effects; $\boldsymbol{\sigma}_{\mathrm{e}}^{2}=$ variance due to residual effects; $\boldsymbol{\sigma}_{\mathrm{p}}^{2}=$ phenotypic variance; $r$ am $=$ additive correlation between direct and maternal effect; $h^{2}{ }_{\mathrm{d}}=$ direct heritability; $\mathrm{m}^{2}=$ maternal heritability; $c^{2}=$ maternal permanent environmental variance as a proportion of $\boldsymbol{\sigma}_{\mathrm{p}}^{2} ; l^{2}=$ litter variance as a proportion of $\boldsymbol{\sigma}_{\mathrm{p}}^{2} ; t_{\mathrm{m}}=$ across-year repeatability of ewe effects $\left[\left(0.25 \boldsymbol{\sigma}^{2}{ }_{\mathrm{a}}+\boldsymbol{\sigma}_{\mathrm{m}}^{2}+\boldsymbol{\sigma}^{2}{ }_{\mathrm{c}}+\boldsymbol{\sigma}_{\mathrm{am}}\right) / \boldsymbol{\sigma}_{\mathrm{p}}{ }_{\mathrm{p}}\right]$; $t_{\mathrm{fs}}=$ full-sib correlation $\left[\left(0.5 \boldsymbol{\sigma}_{\mathrm{a}}^{2}+\boldsymbol{\sigma}_{\mathrm{m}}{ }+\boldsymbol{\sigma}_{\mathrm{c}}^{2}+\boldsymbol{\sigma}_{1}^{2}{ }_{1}+\boldsymbol{\sigma}_{\mathrm{am}}\right) / \boldsymbol{\sigma}_{\mathrm{p}}{ }_{\mathrm{p}}\right] ; h^{2}{ }_{\mathrm{T}}=$ total heritability $\left[\left(\boldsymbol{\sigma}_{\mathrm{a}}^{2}+0.5 \boldsymbol{\sigma}_{\mathrm{m}}^{2}+1.5 \boldsymbol{\sigma}_{\mathrm{am}}\right) / \boldsymbol{\sigma}_{\mathrm{p}}^{2}\right]$; LogL $=\operatorname{logarithm}$ of the likelihood.

${ }^{2}$ Significance levels of alternative models were determined by comparing sequential changes in LogL for Models [1], [2], [3], and [5] and by comparing Models [3] and [4] and Models [5] and [6] to test effects of $\boldsymbol{\sigma}_{\mathrm{am}}$.

$* P<0.05$.

2015) lambs from yearling ewes had WWT that were only 13 and $16 \%$ less than those of 3- through 6-yrold ewes. This discrepancy presumably reflects greater use of supplemental concentrate feeds in NSIP Polypay and Suffolk compared with Katahdin flocks. Effects of type of birth and rearing and of dam age on PWWT of Katahdin lambs were similar to those observed for WWT, which was consistent with greater use of grazed forages in postweaning diets for Katahdin lambs compared with Suffolk and Polypay lambs.

In mammals, growth is influenced by both the genetic potential for growth in the offspring and the maternal environment provided by the dam (Willham, 1972). In estimating genetic parameters for growth traits in sheep, it is therefore important to account for maternal effects, especially in maternal breeds such as the Katahdin. Proper interpretation of parameter estimates derived from animal models for traits influenced by maternal effects depends on both the structure of the data and the model used for the analysis (Safari et al., 2005). Studies on various sheep breeds have shown important maternal effect on lamb BW (Lewis and Beatson, 1999; Bromley et al., 2000; Wilson et al., 2005; Koyuncu and Duru, 2009; Tamioso et al., 2013; Everett-Hincks et al., 2014). The significant $(P<0.05)$ maternal effects on BW in these Katahdin lambs show that failure to properly account for maternal effects leads to overestimation of heritability and may result in unrealistic expectations for improvement of additive breeding values.

Including a maternal permanent environmental effect in the model revealed that variation in BW was due to not only differences in individual genetic potential for growth but also the contribution of the dam environment. This effect was similar from birth to postweaning. Estimates of $c^{2}$ were consistent with averages presented by Safari et al. (2005).

As discussed by Mandal et al. (2006), partitioning the maternal variance into genetic and permanent environmental components is challenging and requires well-structured, multigeneration data sets that include groups of related dams and repeated lambing records. In the current study, maternal genetic effects were larger than permanent environmental effects for BWT and WWT but the 2 effects were similar in importance for WWT. The importance of maternal genetic, but not permanent environmental, effects decreased with lamb age. In NSIP Targhee lambs, maternal genetic and permanent environmental effects also declined with increasing lamb age, but the 2 components were similar in magnitude at 60,120, and $365 \mathrm{~d}$ of age (Notter and Hough, 1997). In NSIP Suffolk and Polypay lambs, the total maternal effects on WWT was larger at $30 \mathrm{~d}$ than at 60 or $90 \mathrm{~d}$ and further declined for lambs weaned at $120 \mathrm{~d}$ (Notter, 1998) but, in contrast to the current 
Table 5. Estimates (SE) for correlations ${ }^{1}$ among birth weight (BWT), weaning weight (WWT), and postweaning weight (PWWT; kg) of Katahdin lambs

\begin{tabular}{lllllll}
\hline \hline Trait 1 & Trait 2 & $r_{\mathrm{d}}$ & $r_{\mathrm{m}}$ & $r_{\mathrm{c}}$ & $r_{\mathrm{e}}$ \\
\hline BWT & WWT & $0.53^{*}(0.05)$ & $0.58^{*}(0.06)$ & $0.51^{*}(0.06)$ & $0.39^{*}(0.01)$ & $0.44^{*}(0.01)$ \\
WWT & PWWT & $0.85^{*}(0.02)$ & $0.99^{*}(0.02)$ & $0.92^{*}(0.02)$ & $0.77^{*}(0.01)$ & $0.81^{*}(0.003)$ \\
BWT & PWWT & $0.45^{*}(0.06)$ & $0.58^{*}(0.08)$ & $0.36^{*}(0.08)$ & $0.33^{*}(0.01)$ & $0.37^{*}(0.01)$ \\
\hline
\end{tabular}

${ }^{1} r_{\mathrm{d}}, r_{\mathrm{m}}, r_{\mathrm{c}}, r_{\mathrm{e}}$, and $r_{\mathrm{p}}$ are direct genetic, maternal genetic, maternal permanent environmental, residual, and phenotypic correlations, respectively. $* P<0.05$.

study, permanent environmental effects were considerably larger than additive maternal effects at all ages in Suffolk lambs and at all ages after $30 \mathrm{~d}$ in Polypay lambs. However, Hanford et al. (2006) reported that maternal genetic effects on lamb WWT were approximately twice as large as maternal permanent environmental effects in Polypay lambs. Maternal effects on PWWT appeared to primarily reflect carryover effects of WWT. Maternal effects on postweaning gains were not significant $(P>0.05)$ in Targhee, Suffolk, or Polypay lambs (Notter and Hough, 1997; Notter, 1998).

The frequency of multiple births is relatively high for Katahdin sheep: only $19 \%$ of the lambs in the current study were born as singles. Consideration of temporary environmental effects unique to full-sibling littermate lambs is therefore indicated for this population. Litter effects arise from temporary environmental effects common to littermates and from dominance genetic effects shared by full-sib lambs. Litter effects in Model [5] accounted for 16 to $19 \%$ of phenotypic variance for these BW and reduced estimates of ewe permanent environmental effects from Model [4] by 2 to $4 \%$. Failure to separate across-year permanent environmental effects of the dam (i.e., $c^{2}$ ) from within-year litter effects in Model [4] underestimated the full-sibling littermate correlation for all BW. Inclusion of litter effects in the model also reduces the importance of records of littermate lambs, compared with full- and half-sib lambs born in different years, in breeding value predictions.

Litter effects in the current study increased slightly from birth to weaning but were similar for WWT and PWWT. The estimate of the litter effect for BWT in our study was the same as that reported by Al-Shorepy and Notter (1998) for lambs born in spring and autumn. Everett-Hincks et al. (2014) reported a lower estimate of 0.10 but Van Wyk et al. (2003) obtained estimates of 0.28 for BWT and 0.22 for WWT in Dormer sheep. In the New Zealand Coopworth sheep, litter effects explained over $30 \%$ of total phenotypic variance for WWT (Lewis and Beatson, 1999). Litter effects accounted for 12 to $37 \%$ phenotypic variance in Hampshire, Polled Dorset, and Romanov lambs (Tosh and Kemp, 1994), but the litter effect in that study included both maternal permanent and temporary environmental effects.
The low negative direct-maternal additive correlation for BW in this population indicated little or no antagonism between direct and maternal effects, and inclusion of this parameter in the model was important only for WWT. Including the direct-maternal covariance in the model slightly increased direct and maternal heritabilities, but the maternal permanent environmental effect stayed the same. This result was consistent with results of Notter (1998), who reported evidence for an antagonistic relationship between additive direct and maternal genetic effects on 60-d WWT in Suffolk $\left(r_{\text {am }}=\right.$ $-0.42, P=0.07)$ and Polypay $(\mathrm{ram}=-0.55, P<0.05)$ lambs. Robison (1981) suggested that there was a general antagonism between direct and maternal genetic effects for WWT. Cundiff (1972) explained that from an evolutionary point of view, a negative covariance between direct and maternal genetic effect prevents species from getting increasingly larger. More negative estimates of direct-maternal correlations for WWT have been reported (Lewis and Beatson, 1999; Neser et al., 2001; Vanimisetti et al., 2007; Kariuki et al., 2010), but positive estimates have also been reported (Nasholm and Danell, 1994; Hanford et al., 2006).

Based on the most appropriate models, direct heritability increased whereas maternal heritability decreased with increasing lamb age. Similar estimates of direct and maternal heritability were reported in Polypay (Hanford et al., 2006) and NSIP Suffolk lambs (Notter, 1998), but lower estimates were reported for Suffolk (Tamioso et al., 2013), NSIP Targhee (Notter and Hough, 1997), and NSIP Polypay lambs (Notter, 1998). Ratios of maternal heritability to direct heritability decreased with age, from $94 \%$ for BWT to $30 \%$ for PWWT, and were consistent with results summarized by Safari et al. (2005). The across-year repeatability of ewe performance was moderate at birth and decreased as lambs became older and less dependent on their dam. The correlation among BW of full-sib lambs was 0.44 for BWT but declined to 0.38 for WWT and 0.39 for PWWT. The total heritability was moderate across $\mathrm{BW}$ and indicated that individual selection for BW would be effective in this population.

Bivariate analyses using a model that contained direct and maternal additive, maternal permanent 
environmental, and residual effects revealed that correlations between adjacent weights were stronger than those between nonadjacent ones and that the largest correlations were between WWT and PWWT. Additive direct and phenotypic correlations between pairs of traits were similar to weighted averages from studies summarized by Safari et al. (2005). Hanford et al. (2006) reported a similar additive genetic correlation between BWT and WWT in Polypay sheep, but Neser et al. (2001) and Kariuki et al. (2010) reported lower correlations of 0.27 and 0.41, respectively, in Dorper sheep, and the phenotypic correlation between BWT and WWT in our study was lower than the estimate of 0.71 presented by Kariuki et al. (2010). Our estimate of maternal genetic correlation between BWT and WWT was similar to the estimate of 0.54 reported by Neser et al. (2001) in Dorper lambs but slightly higher than the estimate of 0.48 reported by Hanford et al. (2006) in Polypay lambs. Similarly, Kariuki et al. (2010) reported a direct genetic correlation between BWT and PWWT of 0.56 but a greater (0.94) phenotypic correlation. Positive correlations between BW in this study indicate that selection to improve any individual weight will result in substantial correlated responses in other BW.

\section{Conclusion}

Moderate estimates of heritability for birth, weaning, and postweaning BW and large positive genetic correlations among these BW in U.S. Katahdin sheep confirms the potential for genetic improvement of BW in this breed. Maternal effects on lamb BW decreased with age as lambs became less dependent on their dams but were still present for postweaning weights and should be included in models to predict breeding values for lamb BW. In sheep breeds that produce twin and triplet lambs, a litter effect should be included in the model to account for the greater resemblance among full-sibling littermate lambs. Failure to properly account for maternal influences of the dam results in overestimation of heritabilities and unrealistic expectations for rates of genetic improvement.

\section{LITERATURE CITED}

Al-Shorepy, S. A., and D. R. Notter. 1998. Genetic Parameters for lamb birth weight in spring and autumn lambing. Anim. Sci. 67:327-332. doi:10.1017/S1357729800010092

Borg, R. C., D. R. Notter, L. A. Kuehn, and R. W. Kott. 2007. Breeding objectives for Targhee sheep. J. Anim. Sci. 85:28152829. doi:10.2527/jas.2006-064

Bradford, G. E., editor. 2003. Breeding and genetics. In: SID sheep production handbook. 2002 ed. American Sheep Industry Association, Centennial, CO. p. 1-80.
Bromley, C. M., G. D. Snowder, and L. D. Van Vleck. 2000. Genetic parameters among weight, proliferacy, and wool traits of Columbia, Polypay, Rambouillet, and Targhee sheep. J. Anim. Sci. 78:846-858. doi:10.2527/2000.784846x

Cundiff, L. V. 1972. The role of maternal effects in animal breeding; VIII. Comparative aspects of maternal effects. J. Anim. Sci. 35:1335-1337. doi:10.2527/jas1972.3561335x

Everett-Hincks, J. M., H. C. Mathias-Davis, G. J. Greer, B. A. Auvray, and K. G. Dodd. 2014. Genetic parameters for lamb birth weight, survival and death risk traits. J. Anim. Sci. 92:2885-2895. doi:10.2527/jas.2013-7176

Gilmour, A. R., B. J. Gogel, B. R. Cullis, S. J. Welham, and R. Thompson. 2015. ASReml user guide release 4.1. Structural specification. VSN International Ltd., Hemel Hempstead, UK.

Hanford, K. J., L. D. Van Vleck, and G. D. Snowder. 2006. Estimates of genetic parameters and genetic trend for reproduction, weight, and wool characteristics of Polypay sheep. Livest. Sci. 102:7282. doi:10.1016/j.livsci.2005.11.002

Kariuki, C. M., E. D. Ilatsia, I. S. Kosgey, and A. K. Kahi. 2010. Direct and maternal (co)variance components, genetic parameters and annual trends for growth traits of Dorper sheep in semiarid Kenya. Trop. Anim. Health Prod. 42:473-481. doi:10.1007/ s11250-009-9446-0

Koyuncu, M., and S. Duru. 2009. Estimates of (co)variance components for direct and maternal effects on birth weight of Karacabey Merino lambs. Turk. J. Vet. Anim. Sci. 33:235-240.

Lewis, R. M., and P. R. Beatson. 1999. Choosing maternal-effect models to estimate (co)variances for live and fleece weight in New Zealand Coopworth sheep. Livest. Prod. Sci. 58:137-150. doi:10.1016/S0301-6226(98)00197-3

Mandal, A., F. W. C. Neser, P. K. Rout, R. Roy, and D. R. Notter. 2006. Estimation of direct and maternal (co)variance components for pre-weaning growth traits in Muzaffarnagari sheep. Livest. Sci. 99:79-89. doi:10.1016/j.livprodsci.2005.06.001

Nasholm, A., and O. Danell. 1994. Maternal effects on lamb weight. In: Proc. 5th World Congr. Genet. Appl. Livest. Prod., University of Guelph, Canada. p. 163-166.

Neser, F. W. C., G. J. Erasmus, and J. B. van Wyk. 2001. Genetic parameter estimates for pre-weaning weight traits in Dorper sheep. 2001. Small Rumin. Res. 40:197-202. doi:10.1016/S09214488(01)00172-9

Notter, D. R. 1998. Genetic parameters for growth traits in Suffolk and Polypay sheep. Livest. Prod. Sci. 55:205-213. doi:10.1016/ S0301-6226(98)00141-9

Notter, D. R., R. C. Borg, and L. A. Kuehn. 2005. Adjustment of lamb birth and weaning weights for continuous effects of ewe age. Anim. Sci. 80:241-248. doi:10.1079/ASC40760241

Notter, D. R., and D. J. Brown. 2015. Effects of birth-rearing type on weaning weights in meat sheep are systematically associated with differences in mean performance among flocks. Genet. Sel. Evol. 47:57. doi:10.1186/s12711-015-0136-2

Notter, D. R., and J. D. Hough. 1997. Genetic parameter estimates for growth and fleece characteristics in Targhee sheep. J. Anim. Sci. 75:1729-1737. doi:10.2527/1997.7571729x

Robison, O. W. 1981. The influence of maternal effects on the efficiency of selection. A review. Livest. Prod. Sci. 8:121-137. doi:10.1016/0301-6226(81)90016-6

Safari, E., N. M. Fogarty, and A. R. Gilmour. 2005. A review of genetic parameter estimates for wool, growth, meat and reproduction traits in sheep. Livest. Prod. Sci. 92:271-289. doi:10.1016/j. livprodsci.2004.09.003 
Tamioso, P. R., J. L. Alberti, L. T. Dias, and R. D. Teixeira. 2013. Estimates of co(variance) components and genetic parameters for growth traits in Suffolk lambs. Cienc. Rural 43:2215-2220. doi:10.1590/S0103-84782013001200016

Tosh, J. J., and R. A. Kemp. 1994. Estimation of variance components for lamb weights in three sheep populations. J. Anim. Sci. 72:1184-1190.

Vanimisetti, H. B., S. P. Greiner, A. M. Zajac, and D. R. Notter. 2004. Performance of hair sheep composite breeds: Resistance of lambs to Haemonchus contortus. J. Anim. Sci. 82:595-604. doi: $10.2527 / 2004.822595 \mathrm{x}$

Vanimisetti, H. B., D. R. Notter, and L. A. Kuehn. 2007. Genetic (co) variance components for ewe productivity traits in Katahdin sheep. J. Anim. Sci. 85:60-68. doi:10.2527/jas.2006-248
Van Wyk, J. B., M. D. Fair, and S. W. P. Cloete. 2003. Revised models and genetic parameter estimates for production and reproduction traits in the Elsenburg Dormer sheep stud S. Afr. J. Anim. Sci. 33:213-222.

Wildeus, S. 1997. Hair sheep genetic resources and their contribution to diversified small ruminant production in the United States. J. Anim. Sci. 75:630-640. doi:10.2527/1997.753630x

Willham, R. C. 1972. The role of maternal effects in animal breeding III. Biometrical aspects of maternal effects in animals. J. Anim. Sci. 35:1288-1293. doi:10.2527/jas1972.3561288x

Wilson, A. J., D. W. Coltman, J. M. Pemberton, A. D. J. Overall, K. A. Byrne, and L. E. B. Kruuk. 2005. Maternal genetic effects set the potential for evolution in a free-living vertebrate population. J. Evol. Biol. 18:405-414. doi:10.1111/j.1420-9101.2004.00824.x 
Reproduced with permission of copyright owner.

Further reproduction prohibited without permission. 